\title{
Alienação e direito da saúde: uma analise dos conselhos de saúde
}

\author{
Alienation and Health Law: an analysis of health councils
}

\section{Fernando Gabriel Lopes Cavalcante}

Graduando pela Universidade Estadual de Feira de Santana. Feira de Santana, Brasil.

Resumo: O presente trabalho pretende fazer uma abordagem da alienação enquanto categoria marxista. O que é a alienação em Marx? Quais as principais repercussões dessa categoria para a compreensão da relação do sujeito com o Estado? São algumas das questões imprescindíveis para dar o impulso inicial de nossa analise. Após o devido tratamento da categoria marxista, passamos a analisar o processo de participação social nos conselhos de saúde. A saúde pública é posta em destaque como uma construção social composta de variantes que vão desde os representantes eleitos pela democracia representativa até as intervenções populares advindas da democracia participativa.

Palavras-chave: Conselho, saúde, direito, alienação.

Keywords: Council, health, law, alienation.

\section{Para uma contextualização introdutória}

A construção histórica dos conselhos de saúde brasileiros guardam profundas conexões com a defesa da democracia e, consequentemente, com o embate contra o regime ditatorial que assolou o Brasil durante longas duas décadas. Os conselhos surgem como resposta de uma articulação, a qual envolveu diversos setores da sociedade civil, iniciada desde o governo Geisel, passando pela constituinte de $88 \mathrm{e}$ sendo determinante para a construção do SUS a partir da Lei 8080 de 1990. De maneira que coexistem atualmente com as secretarias municipais, as secretarias estaduais e o Ministério da Saúde, como ponto de rearticulação de setores da sociedade civil perante o Estado, por via daquilo que se compreende enquanto controle social. Em síntese são espaços democráticos de articulação da sociedade civil resultado de uma articulação da sociedade civil em defesa da democracia. 
Entrando um pouco nos pormenores dessa conexão dialética entre a existência concreta atual dos conselhos (espaço de atuação democrática) e o processo de construção dos conselhos como o de tomada dos espaços institucionais da burocracia-institucional ditatorial, Sarah Escorel nos traz alguns apontamentos que entendemos ser necessários colocar em voga em nossa reflexão. Falando da gênese do movimento sanitário contemporâneo, pontua a autora a inserção de técnicos ligados ao movimento sanitário no interior do aparato burocrático estatal, a partir de determinações que surgiram com o II Plano Nacional de Desenvolvimento do governo Geisel, e como esse distensionamento do regime serviu para a aglutinação de forças políticas contrárias que empurraram o Estado brasileiro em direção à democracia. $\mathrm{O}$ avanço democrático, nesse contexto, veio atrelado à agitação de bandeiras políticas referentes à saúde nos moldes de um sistema público e voltado a saúde coletiva, logo contrárias à política privatista e assistencialista do regime. Utilizando as palavras da autora: "Atuando sob forte pressão do regime autoritário, o movimento sanitário caracterizou-se, gradualmente, como uma força construída a partir da articulação de uma série de propostas contestatórias ao regime" (Escorel e Nascimento e Edler, 2005, p. 67).

Partindo desse contexto de distensionamento, ainda segundo Escorel, diversos espaços contra-hegemônicos foram sendo criados e articulados entre si. Dentre eles o Centro Brasileiro de Estudos da Saúde, a Associação Brasileira de Pós-Graduação em Saúde Coletiva e os Departamentos de Medicina Preventiva. Estes últimos, núcleos dedicados ao estudo da saúde coletiva que para a autora configurariam "o locus a partir do qual começou a se organizar o movimento sanitário, que buscava conciliar a produção do conhecimento e a prática política, ao mesmo tempo em que ampliava seu campo de ação, envolvendo-se com organizações da sociedade civil nas suas demandas pela democratização do país" (Escorel e Nascimento e Edler, 2005, p. 63). Tais espaços de articulação serviriam como grupos de pressão em torno dos quais se ergueria os contornos políticos-institucionais do futuro Sistema Único de Saúde.

Nesse sentido o movimento sanitário avançou até demonstrar sua força política no âmbito da 8ª Conferência Nacional de Saúde, realizada em 1986, ocasião na qual mais de cinco mil representantes da sociedade civil inscreveram no corpo jurídico de nosso país as principais diretrizes da saúde pública brasileira pós-ditadura. Trazendo 
repercussões diretas para a consolidação da saúde enquanto direito gratuito, universal e amparado democraticamente pela participação social, forma como fica transcrito na Constituição de 1988. Especificamente o texto da lei magna nos brinda com a realocação em absoluto daquilo determinado pelo relatório final da Oitava Conferência. Vejamos o que versa sobre isso Escorel:

"A 8 - CNS inaugura, sem base legal, um processo de participação social civil nas deliberações sobre a política de saúde, que será aplicado, aprimorado e regulamentado nas conferências posteriores. Embora tenha sido realizada antes da existência do SUS, o Relatório Final da $8^{\text {a }}$ CNS constituiu o pilar fundamental da proposta da Reforma Sanitária e do SUS, debatido e aperfeiçoado pela Comissão Nacional da Reforma Sanitária que elaborou o texto que seria incorporado como o capítulo da Saúde na Constituição Federal de 1988". (Escorel e Bloch, 2005, p. 97)

Sobre o processo de construção das Conferências nacionais, o qual tem seu ápice participativo com a ocupação da Oitava Conferência pela sociedade civil, momento histórico que não é só o ponto de síntese de um processo anterior, mas o recomeço de um novo processo da reforma sanitária no Brasil, Escorel coloca que "as Conferências de Saúde, a partir da 8ª CNS e, formalmente, a partir da Lei n. 8142/90, constituem parte do processo de Reforma Sanitária, arcabouço legal, político e ideológico construído coletivamente pelo movimento sanitário ao longo das décadas anteriores" (Escorel e Bloch, 2005, p. 95) o que nos arremete à reflexão de que o processo de reforma é um processo constante, sendo fruto da capacidade de interferência do movimento sanitário através das gerações de indivíduos relacionados a esse movimento.

Assim, restou estipulado, a partir do projeto de saúde pública construído pelo movimento sanitário, a determinação de que a participação da comunidade é um principio norteador do Sistema Único de Saúde. Essa peculiaridade fica demonstrada no inciso III do artigo 198 da Constituição Federal, bem como também no inciso VIII do artigo $7^{0}$ da Lei $8080 / 90$, os dois textos inserindo a participação social no âmbito do sistema jurídico brasileiro. A questão então seria como se daria esse processo de participação da comunidade: tal resposta é dada com a Lei 8142/90, a qual vai especificar legalmente a organicidade da estrutura de controle social do Sistema. A partir dessa lei, fica assim delimitado que as instâncias colegiadas do SUS são as Conferências de Saúde e os Conselhos de Saúde. Apontados os Conselhos enquanto órgãos colegiados, em caráter permanente e deliberativo, compostos por 
representantes do governo, prestadores de serviço, profissionais de saúde e usuários, o qual atua na formulação de estratégias e no controle da execução da política de saúde na instância correspondente, inclusive nos aspectos econômicos e financeiros, cujas decisões serão homologadas pelo chefe do poder legalmente constituído em cada esfera do governo. Dessa maneira, a composição formal dos Conselhos os torna um instrumento de poder, delimitador de interferência da sociedade civil nas decisões do Estado referentes à Saúde. Nas palavras de Escorel:

"A partir da Constituição de 1988 e da Lei Orgânica da Saúde (8.080/90 e 8.142/90), conselhos e conferências constituíram um 'formidável sistema nacional de órgãos colegiado' (Carvalho, 1997:93), que institucionalizaram a participação da sociedade civil no processo de formação das políticas de saúde, numa 'co-gestão social' que se processa no interior do aparelho do Estado. Dessa maneira, expressam a 'democratização do acesso ao poder' (Carvalho, 1997:93), constituindo arenas permanentes e temporárias, porém regulares, que possibilitariam a apresentação, a defesa e o debate dos diversos atores sociais com representação setorial" (Trindade Lima et al. org., 2005, p. 95).

Como espaço institucional, a partir de sua consolidação formal, os Conselhos passaram a ser concebidos materialmente. As elaborações formais dos estatutos referentes a cada Conselho, e de suas atribuições atinentes ao controle social de cada instância de poder, passam a ganhar contornos de significação política. Iniciaram-se assim as construções de conselhos estaduais, municipais e locais. Os representantes da sociedade civil passaram a assumir suas posições políticas dentro do espaço institucional criado e exercer a defesa dos interesses atinentes às suas respectivas categorias. Assim, o sistema de controle social passou a se disseminar, estabelecendo um vinculo orgânico entre as superestruturas políticas do estado e da sociedade civil organizada, enraizando uma perspectiva de efetivação do poder de baixo para cima.

Chegamos assim ao limite da nossa contextualização. Colhendo especificações fundamentais para delimitar o recorte epistemológico das observações que faremos a partir de agora. Versando sobre o método materialista e dialético de análise da realidade José Paulo Netto vem nos afirmar que "em Marx, a critica do conhecimento acumulado consiste em trazer ao exame racional, tornando-os conscientes, os seus fundamentos, os seus condicionamentos e os seus limites - ao mesmo tempo em que se faz a verificação dos conteúdos desse conhecimento a partir dos processos históricos reais" (Netto, 2011, p. 18). Portanto, para empreender 
o processo de análise resta imprescindível estabelecer a questão que faz os dados colhidos da realidade demonstrarem os fundamentos do fenômeno social. O que nós indagamos? Qual a questão que vai impulsionar o nosso trabalho investigativo? É o que definiremos no próximo parágrafo.

A principal questão que trabalharemos no presente trabalho é a correlação entre o processo de compreensão dos indivíduos inseridos no espaço de participação social dos conselhos de saúde e a alienação a qual estes indivíduos estão submetidos. De uma forma direta: Qual a correlação entre a alienação e a efetividade dos conselhos de saúde? Requer esta questão, porém, alguns desdobramentos de fundo para que a investigação prossiga. Falaremos desses desdobramentos dentro em breve. Primeiramente, retomando a delimitação dos conselhos de saúde aqui inserida enquanto fruto de um processo histórico de retomada da democracia brasileira, é necessário pontuar aqui que elaboramos até o presente momento o exercício de localizar concretamente o nosso alvo de observação. O conselho de saúde nos aparece aqui em síntese como: um espaço formal, positivado em diversas searas do nosso ordenamento jurídico, que só passa a existir materialmente quando ocupado por setores da sociedade civil e que é resultado concreto do processo histórico de construção da reforma sanitária no Brasil, sendo também (um dos) ponto(s) de partida para o prosseguimento desta.

Em resumo temos uma questão e uma síntese. Sendo que a nossa questão partirá dessa síntese para resolver sua problemática.

Voltando à necessidade de realizar desdobramentos em nossa questão, a primeira repartição do nosso problema se dará justamente em compreender o que vem a ser a tal da alienação. Trazendo a alienação não só como elaboração puramente marxista, mas como acúmulo critico de um processo de rupturas e continuidades empreendido por Marx em relação à Hegel, aos hegelianos, e empreendido, também, pelos marxistas que vieram depois em relação aos seus predecessores.

Em segundo lugar, aí sim, buscaremos estabelecer a correlação entre a alienação e os conselhos de saúde, instrumentalizando a teoria numa dada realidade concreta a ser observada. 
Temos então, da nossa questão inicial: o que é alienação numa perspectiva marxista?, Para assim podermos dar uma resposta a nossa questão original: qual a correlação entre a alienação e a efetividade dos conselhos de saúde?

\section{Do que é a alienação enquanto categoria marxista}

Já estabelecido nosso primeiro limite estratégico - qual seja, o definir em apertada síntese o que vem a ser alienação numa perspectiva marxista - para prosseguirmos com nossa investigação, primeiramente vamos nos ater à premissa de que a alienação é uma categoria social, de forma que numa perspectiva marxista "as categorias não são eternas, são historicamente determinadas e esta determinação se verifica na articulação específica que têm nas distintas formas de organização da produção" (Netto, 2011, p. 49). Uma tomada do enquadramento da alienação enquanto categoria marxista insere-se numa perspectiva de compreender como historicamente determinou-se a construção teórica de tal componente social, a fim de estabelecer o vinculo dialético entre o objeto de análise (alienação) e os sujeitos que o analisam (teóricos), assim como também estabelecendo o vinculo entre o elemento categorial e o fator produtivo-econômico. Nos termos empregados por José Paulo Netto ao referenciar-se em Marx:

"As categorias, diz ele, 'exprimem [...] formas de modo de ser, determinações de existência, frequentemente aspectos isolados de [uma] sociedade determinada' - ou seja: elas são objetivas, reais (pertencem à ordem do ser - são categorias ontológicas) mediante procedimentos intelectivos (basicamente, mediante a abstração), o pesquisador as reproduz teoricamente (e, assim, também pertencem à ordem do pensamento - são categorias reflexivas). Por isso mesmo, tanto real quanto teoricamente, as categorias são históricas e transitórias: as categorias válidas na sociedade burguesa só tem validez no seu marco (um exemplo: trabalho assalariado)" (Netto, 2011, p. 46).

Sejamos cuidadosos então ao fazer uma retomada histórica do desenvolvimento categorial da alienação.

A primeira grande divergência que ocorre no trato com a alienação vem da cisma existente entre os pensadores que posteriormente ganham a alcunha de 'velhos hegelianos' e 'novos hegelianos'. Em grande medida a divergência filosófica de fundo acaba galgando intencionalidades políticas que na ponta tinham como finalidade ou afirmar ou contestar o sistema monárquico prussiano: 
"De um lado, postava-se a ala conservadora, a direta hegeliana, que enfatizava o sistema de Hegel como uma realidade consumada e, através dele, procurava defender a monarquia prussiana. De outro, formou-se a esquerda hegeliana, grupo heterogêneo onde se incluía Marx, Engels, Ruge, Feuerbach, Cieszkówski, Hess, Bauer e outros. A esquerda hegeliana rechaçava o sistema filosófico geral de Hegel e apegava-se ao método dialético deixado pelo filósofo. Do método procurava tirar desdobramentos revolucionários para o combate à monarquia prussiana" (Frederico, 2009, p. 19).

$\mathrm{Na}$ busca por realizar em terras germânicas o mesmo giro revolucionário que ocorrera em França, superando assim o sistema feudal de produção econômica e monárquico de dominação política, os jovens hegelianos puseram-se a questionar a causa do povo germânico, com tão grandes pensadores, não conseguir realizar em sua nação aquilo que ocorreu em terras francesas. Em linhas gerais: Por que o povo alemão não faz a sua revolução burguesa? A resposta que estes pensadores chegaram, então, era de que a grande causa do povo alemão não efetivar sua revolução seria a religião. Explicamos: Naquele período, aquilo que viria posteriormente a ser chamado de Alemanha condizia com um território extremamente dividido em diversos protetorados e principados. De forma que as divisas existentes, cada uma com sua respectiva cobrança de imposto alfandegário, determinavam a existência de um comércio débil, que ao fim determinava a existência de uma burguesia também débil. Qual era então o grande motivo de segregação entre os protetorados germânicos? O embate religioso entre protestantes e cristãos, o qual acabava por ser também um embate político.

Nesse sentido, criticar a religião, para os jovens hegelianos, era impulsionar a ocorrência em solo germânico de um processo revolucionário que acabaria por superar o sistema de dominação política e econômica que até então vigorava, o qual eles eram críticos ferrenhos. Qual foi a categoria reflexiva que estes se utilizaram para executar a sua critica da religião? Justamente a alienação. A alienação religiosa para os jovens hegelianos configurar-se-ia no processo de externar as melhores características humanas a uma entidade metafísica, submetendo-se por consequência ao seu domínio. O que não destoava da compreensão hegeliana do processo de alienação, com uma única diferença de que para Hegel e os seguidores mais conservadores do seu sistema filosófico o processo de alienação compreendia um esforço de libertação do gênero humano das amarras as quais a matéria o 
submetia. Sobre esse ponto vejamos o que diz Karl Marx em sua obra "A Ideologia Alemã":

\begin{abstract}
"Os velhos-hegelianos tinham a tudo compreendido, com a compreensão de tudo ser reduzido a uma categoria lógica de Hegel. Os jovens-hegelianos a tudo criticaram, porém subscrevendo (unterschoben) tudo como representações religiosas ou declarando-o teológico. Os jovens-hegelianos concordam com os velhos-hegelianos na crença no domínio da religião, dos conceitos, do universal no mundo existente. Só que uns combatem o domínio como usurpação, e outros o celebram como legítimo" (Marx e Engels, 2009, p. 22)
\end{abstract}

Os primeiros passos do jovem Marx em direção a uma autonomia teórica em relação aos seus pares jovens-hegelianos passaria então, justamente, por um acerto de contas com os estes. Nesse sentido, uma das questões que levariam Marx a se afastar teoricamente dos seus conterrâneos, para além de outras tantas de ordem filosóficas que não cabem aqui por falta de espaço e de tempo, seria justamente o aprisionamento de determinados teóricos às ponderações em relação à alienação religiosa. Entendia Marx que a categoria não circunscrevia excepcionalmente o campo religioso, havendo outros campos de observação nos quais a alienação serviria como ponto fecundo de abordagem para a compreensão dos fenômenos sociais: a economia, o trabalho e a política seriam os principais exemplos.

Um dos esforços da teorização marxista - frisando o plural para que não fique latente que a divergência entre Marx e os jovens hegelianos seja tão-somente de objeto - portanto, seria o de realocar as observações advindas da utilização da alienação enquanto categoria do campo religioso para inseri-las em outros campos da atuação humana. Além disso, na perspectiva de compreender o processo de cristalização da alienação, Marx, em contraponto aos teóricos hegelianos, concebe uma análise que parte do individuo. Não individuo em abstrato, mas o individuo pensado no real, no concreto. A alienação surgindo como resposta a um processo histórico no qual o individuo, ao produzir e reproduzir os seus meios de subsistência, acaba por produzir e reproduzir também a consciência ideológica: "Como exteriorizam [äußern] a sua vida, assim os indivíduos o são. Aquilo que eles são coincide, portanto, com a sua produção, com o que produzem. Aquilo que os indivíduos são depende, portanto, das condições materiais da sua produção" (Marx e Engels, 2009, p. 25). Há de se ter um entendimento de que a alienação não está posta enquanto construção natural, mas sim empreendimento social que é obra da ação e intervenção política de indivíduos. Qual é então a gênese histórica da alienação? Senão vejamos. 
Primeiramente, partindo do individuo, da forma como 0 individuo historicamente produz e reproduz a sua vida, Marx elabora que em determinado momento ocorre aquilo que ele chama de divisão social do trabalho. Uma distribuição das atribuições de cada individuo dentro da vida em sociedade. A qual originalmente não é mais do que a divisão sexual do trabalho e posteriormente acaba por adquirir especificações cada vez mais complexas:

"A divisão do trabalho só se torna realmente divisão a partir do momento em que surge uma divisão do trabalho material e espiritual [geistigen]. A partir desse momento, a consciência pode realmente dar-se à fantasia de ser algo diferente da práxis existente, de representar realmente alguma coisa sem representar - a partir desse momento, a consciência é capaz de se emancipar do mundo e de passar à formação da teoria 'pura'” (Marx e Engels, 2009, p. 45)

Esse cisma existente entre o trabalho material (braçal) e o espiritual (intelectual) é uma das principais causas de manifestação da alienação. Por conta da separação existente entre essas modalidades de trabalho aquele individuo que fica encarregado de empreender o trabalho braçal acaba por ser lesado de compreender a totalidade do processo produtivo. Haja vista que há alguém que pensa o processo que será executado por outro, o segundo acaba tendo acesso a um horizonte de informações mais atrofiado que o primeiro. Essa situação se prolongando historicamente faz com que o agrupamento de indivíduos habituados a exercer o trabalho braçal e os indivíduos habituados a exercer o trabalho intelectual acabem, cada qual de acordo com a forma como adquirem seus meios de subsistência, por assumir uma consciência de classe.

De outro modo, o fato de que, a partir do advento do capitalismo, os meios de produção e o produto do trabalho passam a não mais pertencer (ser propriedade) do trabalhador que realiza efetivamente o processo, gera assim outra manifestação da alienação. Ao ter que entregar o fruto do seu trabalho ao proprietário dos meios de produção, o indivíduo que realizou concretamente o processo produtivo passa a enxergar o seu trabalho de forma estranhada. A propriedade entra ai como um componente extremamente valioso para a compreensão da alienação.

Assim, no processo histórico do surgimento da propriedade: primeiramente encontramos uma modalidade de propriedade tribal na qual havia uma divisão do trabalho eminentemente natural e ligada à divisão interna da família patriarcal, onde a propriedade (fundiária, por exemplo) figurava enquanto ente interligado a uma 
coletividade, gerida de forma a satisfazer as necessidades individuais e comunitárias. Para por fim, com a revolução industrial e as revoluções burguesas do século XIX, termos a consolidação de uma propriedade individual garantido pelo Estado liberal (e reforçada pelo código civil) e a supressão completa da propriedade coletiva. O panorama da evolução da propriedade demonstra uma tendência a ir se deslocando do controle social pela comunidade, para ir cada vez mais tornando-se uma entidade individualista e por último se tornar uma entidade deslocada completamente do controle do indivíduo, inclusive exercendo dominação sobre este. Essa força que escapa ao controle do homem e o esmaga, compelindo-o e oprimindo-o, em Marx, é a manifestação concreta máxima da alienação, sendo o Estado a síntese dessa força alienante.

Para conceber a sua teoria da alienação do trabalho, mais precisamente na obra intitulada manuscritos econômico-filosóficos, Marx teoriza a respeito de 3 modalidades de estranhamento. A primeira referindo-se justamente ao estranhamento que o trabalhador é submetido quando o seu objeto de trabalho não o pertence mais, sendo algo que é retirado deste ao fim do processo produtivo:

"A exteriorização (Entäusserung) do trabalhador em seu produto tem o significado não somente de que o trabalho se torna um objeto, uma existência externa (äussern), mas, bem, além disso, [que se torna uma existência] que existe fora dele (ausser ihm), independente dele e estranha a ele, tornando-se uma potência (Macht) autônoma diante dele, que a vida que ele concedeu ao objeto se lhe defronta hostil e estranha" (Marx, 2004, p. 81)

A segunda modalidade versa sobre 0 ato de produção em si, dentro da própria atividade produtiva, encarando o esforço produtivo como algo exercido de forma não natural, mas extremamente custosa ao individuo. Marx chama essa segunda forma de estranhamento como estranhamento de si, enquanto a outra forma de estranhamento da coisa:

"Primeiro que o trabalho é externo (äusserlich) ao trabalhador, isto é, não pertence ao seu ser, que ele não se afirma, portanto, em seu trabalho, mas nega-se nele, que não se sente bem, mas infeliz, que não desenvolve nenhuma energia física e espiritual livre, mas mortifica sua physis e arruina o seu espírito. O trabalhador só se sente, por conseguinte e em primeiro lugar, junto a si [quando] fora do trabalho e fora de si [quando] no trabalho" (Marx, 2004, p.82-83)

A terceira forma de estranhamento, muito mais complexa e extrato dialético das outras duas, parte de uma premissa apontada por Marx de que o homem é um ser genérico, tanto quando se relaciona com o outro enquanto objeto, quanto quando 
se relaciona consigo mesmo enquanto gênero vivo e quando se relaciona consigo mesmo enquanto ser universal. Restando que "em geral, a questão de que o homem está estranhado do seu ser genérico quer dizer que um homem está estranhado do outro, assim como cada um deles está estranhado da essência humana" (Marx, 2004, p. 86).

Nesse sentido o que delimita ontologicamente a alienação em Marx é um processo de externalização. Tal qual os jovens hegelianos compreendiam a alienação religiosa - uma transferência de características humanas para uma entidade divina a alienação em seus mais variados aspectos, acaba transversalmente enquadrandose num processo de transferência de caracteres humanos (subjetivos) a um determinado objeto. A partir dessa demonstração cabe a reflexão de que o gênero humano acaba por deslocar para as coisas uma centralidade na organização da sociedade que arrasta o próprio sujeito humano para um espaço de relativa invisibilidade. Assim, ao alienar valores subjetivos aos objetos que o rodeia materialmente, o homem acaba por tornar-se objeto. Isso se deve a uma incompreensão do sujeito de que o processo produtivo e organizativo da sociedade se dá a partir de sua ação subjetiva, uma incompreensão de que o trabalho realizado por ele é o fator gerador que cria o meio social que o rodeia.

\section{Um retorno aos conselhos: alienação e participação social}

Trazendo de volta a questão dos conselhos, para compreender a correlação entre a alienação e o sistema de controle social do SUS, nos permitiremos primeiramente explorar como se organiza internamente essa estrutura. A resolução 333 do Conselho Nacional de Saúde é a que introduz de forma geral como deve ser estabelecida a representatividade dos Conselhos. Em síntese devem caber aos conselhos acolher as vozes dos usuários, dos trabalhadores e dos gestores do SUS. Assim busca-se uma interligação entre as políticas públicas de saúde gestadas pelo Estado e a sociedade civil. A partir dessa divisão é que empreenderemos nossa análise.

Iniciando com a afirmação de que o trabalho alienado tem como modalidade em Marx o estranhamento que acomete o trabalhador em sua relação com o produto do trabalho, pergunta-se: o que produz o trabalhador da saúde? O seu serviço está interligado com um objeto (a saúde) extremamente subjetivo, relacionada diretamente 
a uma condição inerente a outro sujeito (o paciente). Além disso, não cabe mais à saúde enquanto conceito uma compreensão restrita, ela compreende um fenômeno social que amplia-se em direção a outros valores sociais. A saúde não mais é saúde enquanto bem-estar tão-somente físico, mas vem revestida também de um bem-estar psíquico e de um bem-estar socio-político. A educação, a urbanidade, o meio ambiente, a segurança, todos esses vetores sociais interferem diretamente na saúde e são causas e consequências dialéticas do como manifesta-se os níveis de qualidade de saúde de uma comunidade.

Assim, são na realidade concreta da comunidade que estão inseridas as contradições que dão causa, lá na ponta, aos problemas individuais de saúde que requerem o serviço do trabalhador da saúde. Esse serviço acaba por admitir nesse plano uma modalidade explicita de trabalho alienado a partir do momento em que o trabalhador da saúde não vislumbra em seu horizonte de realidade a totalidade de questões que dão razão a existência deles. Usando um exemplo, a falta de saneamento básico de uma determinada comunidade tem um potencial de causa de problemas de saúde que lá na ponta o trabalhador não conseguirá solucionar efetivamente tratando apenas da eliminação dos esquistossomos infectantes das crianças do local. Nesse sentido essa falta de compreensão da totalidade é causa da alienação do trabalhador da saúde, pois desconecta o seu trabalho de uma intervenção direta nas contradições que dão causa aos problemas de saúde que tem de se debruçar cotidianamente.

A participação dos trabalhadores da saúde nos conselhos acaba por adquirir um caráter aproximativo deste com a realidade concreta na qual este está inserido. Isso tem um caráter desalienante não só para que este delimite de uma forma mais profunda em qual posição do sistema de organização produtiva e social ele está inserido, como também no sentido de (re)conectar o seu trabalho braçal (material) ao espirito que dá azos pensados a sua condição de trabalhador. Isso (essa desalienação) tem implicações políticas diretas: é muito mais fácil perceber a necessidade de lutar por melhores condições de trabalho quando se percebe que a sua condição de trabalho tem vínculos diretos com a forma como está manifestandose a qualidade da saúde de um determinado local.

Se para os trabalhadores, que pertencem materialmente à Unidade Básica de Saúde - ao SUS - e enxergam cotidianamente aos problemas na ponta do processo, 
ocorre um afastamento destes e relação à totalidade contraditória que dá origem aos problemas, para os usuários do sistema esse afastamento se dá num grau ainda maior. Enquanto os trabalhadores da saúde encaram suas atribuições enquanto objeto do seu trabalho, portanto a ser ofertado a outro sujeito, os usuários do sistema de saúde acabam por efetivamente encararem esse serviço enquanto um objeto a ser recolhido do sistema. Mesmo que o sistema de saúde seja público e gratuito, portanto pertencente ao usuário enquanto detentor do direito à saúde, essa é uma percepção extremamente diluída. Há formalmente um pertencimento do SUS ao usuário, mas materialmente esse espaço é encarado pelo usuário como pertencente ao Estado, portanto alienado do seu controle e entregue a uma entidade detentores de poderes superiores. Essa situação por si já demonstra uma incoerência, a partir do momento que a própria existência material do Sistema dá-se com a utilização econômica dos impostos que são retirados do usuário enquanto contribuinte. Ora, o quanto alienado economicamente de cada indivíduo que compõe a comunidade é justamente a força econômica que materializa o aparelho institucional que o mesmo individuo acaba por considerar alienado de seu controle.

A abertura institucional viabilizada pela existência dos conselhos enquanto órgãos destinados ao controle social do Sistema acaba por abrir a possibilidade de contornar essa contradição. Logicamente o poder do Estado perante os conselhos continua sendo hegemônico, logicamente existe uma dificuldade tremenda no plano fático de viabilizar a própria dinâmica participativa nesses espaços, mas essa abertura indica uma possibilidade de reagrupamento da sociedade civil, e no exercício de suas atribuições democráticas podem vir futuramente a ocupar e direcionar esse espaço. A questão colocada então é a de que o individuo que dispende esforços econômicos para viabilizar materialmente a existência do sistema, tem a possibilidade de reconectar-se a esse esforço alienado acumulado nas mãos do Estado. De maneira oposta, também os problemas da saúde pública da comunidade, para o individuo participante do conselho, deixam de serem problemas apartados de seu controle e de atribuição exclusiva do Estado e passam a serem problemas passíveis de resolução a partir da ação política dos indivíduos organizados a partir do conselho.

Colocando-se diametralmente opostos aos usuários - e de certa forma também aos trabalhadores - os gestores acabam por assumir uma posição 
sensivelmente importante para compreender o processo de alienação (e desalienação) que envolve os conselhos de saúde. Primeiramente os gestores representam formalmente o Estado, personificam materialmente a decisão diante das questões que envolvem a saúde pública de uma dada comunidade, mesmo que essa decisão seja condicionada e requerida por uma contextualização fática, por uma correlação de interesses políticos. Mas com a instrumentalização dos conselhos de saúde o que ocorre é um certo rompimento paradigmático com a forma precedente que o Estado tinha de lidar com as situações de poder envolvendo a saúde. Senão vejamos.

Seguindo as palavras de Suelli Gandolfi Dallari, as primeiras experiências de inserção do Estado na saúde pública inicia-se com a teorização daquilo que veio a se chamar cameralismo. Leibniz foi um dos principais pensadores a escrever sobre o tema, "concordando com a ideologia hegemônica na Alemanha no final do século XVII, que afirmava ser o crescimento populacional a manifestação primeira da prosperidade e bem-estar de um povo e que, portanto, um bom governo deve agir para proteger a saúde de seus súditos" (Dallari, 2003, p. 41). Essa forma de encarar a saúde pública encontrava na manutenção de corpos saudáveis uma forma de aumentar o poder do Estado, os corpos saudáveis sendo a base da força política, objetos pertencentes ao Estado, posicionado o Estado enquanto fim último - sujeito central do processo - ao qual os indivíduos deveriam prestar subserviência. A partir do advento do liberalismo o paradigma de saúde pública dominante era o de que o Estado não deveria interferir em questões vinculadas à saúde senão subsidiariamente, cabendo ao individuo tratar autonomamente dessas questões. $\mathrm{O}$ Estado de Bem Estar social insere um estrutural estatal que permite uma interferência direta nas questões de saúde pública. Por fim, as prerrogativas do neoliberalismo vêm tensionando por um afastamento e pelo reposicionamento do Estado num espaço subsidiário em relação aos indivíduos no cuidado com a saúde.

Os conselhos são criados num contexto de implementação das medidas neoliberais na sociedade brasileira, servindo, portanto, como contraponto de resistência ao deslocamento do Estado para um espaço subsidiário. Na defesa por um sistema de saúde público e gratuito estes espaços institucionais realização uma integração entre a sociedade civil e o Estado, permitindo tanto a negação de um 
cuidado com a saúde individualista quando um cuidado estritamente vinculado a uma entidade política alienada da população.

Os gestores acabam por cumprir um papel de ter de dobrar a institucionalidade perante a sociedade civil, não por opção política, mas mediante a força das próprias normas constitucionais e infraconstitucionais que positivam formalmente os conselhos. Essa obrigatoriedade dá-se, pois sem a realização desse processo de participação questões essenciais como o próprio financiamento da saúde são travadas. Em grande medida o processo decisório do gestor de saúde tem de passar pelo crivo e deliberação dos conselheiros de saúde. Essa conexão, muitas vezes forçada, do gestor com a sociedade civil acaba por delimitar um menor apartamento da entidade estatal das demandas cotidianas da população.

Por fim, para além das analises transpostas aqui acerca da reinserção desalienante do individuo no âmbito da participação social nos conselhos, fica latente também que a inserção individual no processo histórico de reforma das estruturas sanitárias brasileiras acaba por reafirmar a condição de espaço desalienador dos conselhos de saúde.

\section{Para não concluir}

O rasgo paradigmático causado pela atuação do movimento sanitário ao pressionar o Estado brasileiro acabou por nos brindar com a concretização de um espaço sui generis de atuação democrática. No qual a reintegração de atores sociais distintos em seus posicionamentos e interesses acaba por ter como norte estratégico o controle social do Estado no que tangencia as questões referentes à saúde. Essa reintegração acaba por nos trazer a questão que nos acompanhou até aqui: Qual a correlação entre a alienação e a efetividade dos conselhos de saúde?

Efetividade acaba por ser apresentado como contornos não só objetivos como também subjetivos. O limiar existente entre a compreensão do indivíduo acerca da totalidade que o circunda e de qual espaço ocupa este dentro dessa totalidade guarda significações de extrema importância para delimitarmos a participação social. A participação no âmbito de uma estrutura como o conselho cumpre com a perspectiva de reconexão do humano enquanto individuo com o humano enquanto ser social, enquanto gênero vivo impulsionador do processo de transformação da sociedade. Dito isto pois a estrutura de um conselho guarda peculiaridades 
coletivistas: não há apenas o individuo em busca de seus interesses numa estrutura como esta, há o individuo em interação concreta com o outro, há o individuo sendo levado a se deslocar de seu local de pertencimento para estabelecer a construção de síntese com diversos outros indivíduos. Essa síntese entre interesses diversos, entre construções individuais diversas, em direção à construção de definições ditas universais.

Como então tornar essa síntese senhora o máximo possível de uma aproximação com valores universais senão abrangendo o maior numero possível de vozes interlocutoras do processo de construção dessa síntese? Nesse sentido, quanto maiores as pontuações divergentes, quanto mais indivíduos inseridos em espaços de produção e reprodução do sistema de saúde, maior a probabilidade de que com o choque de posições o conselho aumente sua efetividade objetiva.

Assim, a conjuntura atual, no qual o individuo é constantemente apartado do processo de tomada de decisões, alienando-se politicamente, guarda em seu interior diversos obstáculos à participação. $O$ individuo que tem de si retirado o objeto do seu trabalho - primeira modalidade de alienação nos Manuscritos Econômico-filosóficos e que encara o processo de produção do seu objeto de trabalho enquanto algo estranhado de sua vida privada - segunda modalidade de alienação nos Manuscritos Econômico-filosóficos - acaba invariavelmente por não compreender o mundo que o circunda enquanto resultado da sua atuação enquanto individuo. Dessa incompreensão restam as afirmações de que os problemas estruturais da sociedade - dentre estes o da saúde - são questões dadas e que por isso (supostamente) devem ser naturalizadas.

Finalmente, o espaço de construção coletiva dos conselhos acaba por ser constantemente esvaziados e não conseguem cumprir objetivamente com as demandas sociais que deveriam suprir. Esse esvaziamento é reflexo direto da conjuntura de alienação a qual o povo é submetido. Assim como o conselho guarda em si a potencialidade de reverter o processo de alienação quando é configurado enquanto espaço de reintegração dos sujeitos participantes.

\section{Referências}

DALLARI, Sueli Gandolfi. Direito Sanitário. Em: BRASIL. Ministério da Saúde. Direito sanitário e saúde pública. Brasília: Ministério da Saúde, 2003. 
ESCOREL, Sarah. Reviravolta na saúde: origens e articulação do movimento sanitário. Rio de Janeiro: Editora Fiocruz, 2009, 208 p.

ESCOREL, Sarah; NASCIMENTO, Dilene Raimundo de e EDLER, Flavio Coelho. As Origens da Reforma Sanitária e do SUS. Em: TRINDADE LIMA, Nísia [et al] (org). Saúde e democracia: historia e perspectivas do SUS. Rio de Janeiro: Editora Fiocruz, 2006. $504 \mathrm{p}$.

ESCOREL, Sarah e BLOCH, Renata Arruda de. As Conferências Nacionais de Saúde na Construção do SUS. Em: TRINDADE LIMA, Nísia [et al] (org). Saúde e democracia: historia e perspectivas do SUS. Rio de Janeiro: Editora Fiocruz, 2006. $504 \mathrm{p}$.

FREDERICO, Celso. O Jovem Marx: 1843-1844: as origens da ontologia do ser social. (2 ed.) São Paulo: Expressão Popular, 2009. 216 p.

MARX, Karl e ENGELS, Friedrich. A ideologia alemã. São Paulo: Expressão Popular, 2009. $128 \mathrm{p}$.

MARX, Karl. Manuscritos Econômico-Filosóficos. São Paulo: Editora Boitempo, 2004. $176 \mathrm{p}$.

NETTO, José Paulo. Introdução ao Estudo do método de Marx. São Paulo: Expressão Popular, 2011, 64 p. 